\title{
FATORES QUE INFLUENCIAM NA PREVENÇÃO DE AGRAVOS FRENTE AO USO DE AGROTÓXICOS NA ATIVIDADE RURAL: revisão integrativa
}

\section{FACTORS THAT INFLUENCE DISEASE PREVENTION FRONT OF USE OF PESTICIDES IN RURAL ACTIVITY: integrative review}

\section{Cibelle Mello Viero', Silviamar Camponogara²}

\section{RESUMO}

$\mathrm{Na}$ atualidade, enfrentamos sérios desafios, dentre os quais, a complexidade da problemática ambiental que demanda da sociedade um agir ambientalmente responsável. A exemplo disso, o uso de agrotóxicos é um tema que vem despertando atenção crescente, tendo em vista suas consequências para a saúde dos trabalhadores rurais. Frente a isso, objetivou-se avaliar, na literatura, fatores que influenciam na prevenção de agravos frente ao uso dos agrotóxicos na atividade rural. Estudo de revisão integrativa. A coleta de dados ocorreu em junho de 2013. 0 corpus de análise foi composto de 14 artigos. As produções apontam dados relacionados ao não uso de Equipamentos de Proteção Individual (EPI's), desconhecimento dos riscos no uso desses produtos e carência de políticas governamentais relativas ao tema. Isso exige dos profissionais de enfermagem uma postura ativa diante da problemática, com vistas à minimização desses riscos.

Descritores: Enfermagem; Saúde da População Rural; Praguicidas.

\section{ABSTRACT}

Nowadays, we face serious challenges, among which, the complexity of environmental problems that society demand one act environmentally responsible. As an example, the use of pesticides is a topic that has attracted increasing attention in view of its consequences for the health of farm workers. Faced with this, it was aimed to evaluate, in the literature, factors that influence the prevention front aggravation to the use of pesticides in rural activity. Study integrative review. Data collection took place in June 2013. The corpus analysis was composed of 14 articles. Yields indicate data related to non-use of Personal Protective Equipment (PPE), ignorance of the risks in these products and the lack of government policies relating to the topic. This requires nursing professionals an active attitude on of the problematic, with a view to minimizing these risks.

Descriptors: Nursing; Rural Health; Pesticides.
${ }^{1}$ Mestre em Enfermagem pela Universidade Federal de Santa Maria (UFSM), Santa Maria, RS, Brasil.

2 Doutora em Enfermagem pela Universidade Federal de Santa Catarina (UFSC), Florianópolis, SC, Brasil. 


\section{Introdução}

$\mathrm{Na}$ atualidade, enfrentamos sérios desafios, dentre os quais, a complexidade da problemática ambiental que demanda da sociedade um agir ambientalmente responsável, tendo em vista o acelerado processo de destruição ambiental que vivenciamos e as ameaças à sobrevivência do planeta e da humanidade. A exemplo disso, o uso de agrotóxicos é um tema que vem despertando atenção, tendo em vista suas consequências para a saúde humana, causadas pelo seu uso crescente e, às vezes, inadequado.

Destarte, o Brasil é, atualmente, o maior consumidor de agrotóxicos no mundo, devido ao nosso atual modelo de desenvolvimento econômico e agroexportador. Face a isso, o processo de modernização tecnológica iniciado nos anos cinquenta, com a chamada "revolução verde", somado ao discurso da "modernização da economia rural", modificou profundamente as práticas agrícolas, gerou mudanças tecnológicas nos processos de trabalho e aumentou a produtividade brasileira'.

Esses incrementos na produção agrícola afetaram diretamente a saúde humana, principalmente dos trabalhadores rurais e dos ecossistemas, com o crescimento descontrolado de pragas como insetos, fungos e roedores, e expulsou a fauna e a flora de seus habitats, com a destruição dos ecossistemas e a sua substituição por novas áreas de expansão de atividades agropecuárias ${ }^{1}$. Diante disso, os impactos à saúde da população são amplos, atingindo principalmente os trabalhadores rurais, que têm contato direto com os agrotóxicos².

Os agrotóxicos estão entre os fatores de risco mais relevantes para a saúde da população, especialmente para a saúde dos trabalhadores expostos e para o meio ambiente ${ }^{3}$. Por representar um problema de saúde pública e pelas repercussões no âmbito da saúde de trabalhadores e de comunidades que vivem próximas às grandes áreas de produção, o setor saúde vem buscando definir e implementar ações voltadas para atenção integral das populações expostas a agrotóxicos ${ }^{4}$.

Além disso, as evidências disponíveis sobre os prejuízos dos agrotóxicos à saúde alertam para a gravidade da questão, na medida em que dialogam com os grupos de agravos prevalentes no perfil de morbimortalidade do país². Nessa perspectiva, os agrotóxicos são substâncias químicas que geram uma série de efeitos nocivos à saúde humana.

Os agrotóxicos são genericamente denominados praguicidas ou pesticidas. As classes toxicológicas são indicadas por meio das cores dos rótulos, sendo classe I - faixa vermelha (extremamente tóxico), classe II - faixa amarela (altamente tóxica), classe III - faixa azul (medianamente tóxico) e classe IV - faixa verde (pouco ou muito pouco tóxico) ${ }^{5}$. De acordo com a classe química a que esses produtos pertencem e o tipo de exposição, podem causar desde afecções, como dermatites, até alguns tipos de doenças mais graves, como o câncer ${ }^{6}$.

Por isso, enfermagem precisa mobilizar-se para enfrentar esta situação e buscar alternativas para reduzir ou eliminar a contaminação dos trabalhadores no campo pelos agrotóxicos. A conscientização dos agricultores e consumidores quanto aos elevados riscos para a saúde humana e para o meio ambiente da utilização de agrotóxicos é fundamental para mudar essa realidade ${ }^{7}$.

A relevância desse estudo concentra-se na necessidade de aprofundar o conhecimento acerca da questão da saúde do trabalhador rural e o uso de agrotóxicos. Frente a essa reflexão, é mister que os profissionais de enfermagem reconheçam os riscos a que esses trabalhadores rurais estão expostos, para que esse conhecimento seja incorporado na prática assistencial.

Diante disso, a questão norteadora deste estudo foi: Quais fatores influenciam na prevenção de agravos frente ao uso dos agrotóxicos na atividade rural? A fim de responder essa questão, objetivou-se analisar, na literatura, a influência desses fatores na prevenção de agravos frente ao uso dos agrotóxicos na atividade rural.

\section{Metodologia}

Estudo de revisão integrativa, a qual tem a finalidade de reunir e sintetizar resultados de pesquisas sobre determinado tema, de forma sistemática e ordenada, auxiliando para o aprofundamento do conhecimento da questão investigada ${ }^{8}$. Para elaboração do estudo, foram seguidos os seguintes passos: identificação do tema, amostragem ou busca na literatura, categorização dos estudos, avaliação dos estudos, interpretação dos resultados e a síntese do conhecimento evidenciado nos artigos analisados ou apresentação da revisão integrativa9 .

A busca bibliográfica nas bases de dados Literatura Latino-Americana e do Caribe em Ciências da Saúde (LILACS) e National Center for Biotechnology Information (NCBI) na U.S. National Library of Medicine (NLM) - PUBMED, sem recorte temporal. Utilizou-se como estratégia de busca na LILACS: "PRAGUICIDAS" [Descritor de assunto] and 
("saúde do trabalhador rural") or "TRABALHADORES RURAIS" [Descritor de assunto], com um total de 54 publicações encontradas. E no PUBMED utilizou-se a seguinte estratégia de busca: ((pesticides) AND rural health) AND occupational risks, com os filtros de idiomas Inglês, Espanhol, Português e Humanos com um total de 107 documentos encontrados. A coleta de dados ocorreu em junho de 2013.

O somatório de produções científicas disponíveis nos bancos de dados foi de 161 documentos. Os critérios de inclusão foram: artigos de pesquisa na temática dos agrotóxicos, envolvendo trabalhadores rurais, com texto completo, disponível em suporte eletrônico. Os critérios de exclusão foram documentos que não estavam disponíveis gratuitamente e artigos derivados de pesquisa sobre relação do uso de agrotóxicos e o desenvolvimento de patologias como Parkinson, câncer, depressão, tentativa de suicídio, alcoolismo entre outras, ou seja, as intoxicações pelo uso dos agrotóxicos, pois essas, por suas especificidades, correspondiam às consequências do uso de agrotóxicos e não à questão do estudo.

A seleção dos artigos foi desenvolvida por meio da leitura dos títulos e dos resumos, sendo que foram excluídas 147 publicações e o corpus de análise foi composto de 14 artigos. Para a análise documental, foi utilizado um quadro contendo o título do artigo, o ano de publicação, o país de origem, além das características metodológicas do estudo e resultados encontrados. A apreciação das informações extraídas foi realizada na forma descritiva, possibilitando ao profissional de enfermagem conhecer os fatores que influenciam na prevenção de agravos frente ao uso de agrotóxicos na atividade rural.

\section{Resultados e Discussão}

Para elucidar o leitor em relação ao corpus de análise das publicações científicas, foi elaborado um quadro contendo uma descrição dos artigos analisados.

Quadro 1 - Descrição dos artigos da revisão integrativa

\begin{tabular}{|c|c|c|c|c|}
\hline Título/ Referência (*) & Ano/País & $\begin{array}{l}\text { Delineamento/ } \\
\text { Número de } \\
\text { Participante }\end{array}$ & Intervenções & $\begin{array}{c}\text { Considerações do } \\
\text { estudo }\end{array}$ \\
\hline $\begin{array}{l}\text { Agrotóxicos: Risco à Saúde } \\
\text { do Trabalhador Rural }\end{array}$ & 2004/Brasil & Pesquisa bibliográfica & $\begin{array}{l}\text { Levantamento } \\
\text { dos principais } \\
\text { fatores de risco de } \\
\text { intoxicação por } \\
\text { agrotóxicos }\end{array}$ & $\begin{array}{c}\text { Necessidade de restringir } \\
\text { o uso dos agrotóxicos } \\
\text { mais perigosos no intuito } \\
\text { de diminuir os casos de } \\
\text { intoxicação aguda, além } \\
\text { de investimento em } \\
\text { programas preventivos de } \\
\text { saúde }\end{array}$ \\
\hline $\begin{array}{l}\text { Comunidade pomerana e } \\
\text { uso de agrotóxicos: uma } \\
\text { realidade pouco conhecida }\end{array}$ & 2009/Brasil & $\begin{array}{l}\text { Estudo transversal } \\
\text { realizado com } 151 \\
\text { famílias }\end{array}$ & $\begin{array}{l}\text { Análise baseada } \\
\text { em estatísticas } \\
\text { descritivas e } \\
\text { modelos de } \\
\text { regressão logística }\end{array}$ & $\begin{array}{l}\text { A probabilidade de um } \\
\text { indivíduo apresentar } \\
\text { algum problema de } \\
\text { saúde está relacionada } \\
\text { com o uso de } \\
\text { agrotóxicos e o grau de } \\
\text { escolaridade é um fator } \\
\text { importante para o uso } \\
\text { de equipamentos de } \\
\text { proteção }\end{array}$ \\
\hline $\begin{array}{l}\text { Agrotóxicos e saúde: } \\
\text { realidade e desafios para } \\
\text { mudança de práticas na } \\
\text { agricultura }\end{array}$ & 2009/Brasil & $\begin{array}{l}\text { Pesquisa qualitativa } \\
\text { com } 38 \text { agricultores } \\
\text { familiares }\end{array}$ & $\begin{array}{l}\text { Caracterização } \\
\text { do contexto } \\
\text { e das práticas } \\
\text { relacionadas ao } \\
\text { uso de agrotóxicos }\end{array}$ & $\begin{array}{l}\text { A maioria dos } \\
\text { informantes acredita que } \\
\text { agrotóxicos podem afetar } \\
\text { sua saúde, apresenta } \\
\text { preocupação com o } \\
\text { consumidor e gostaria } \\
\text { de conhecer formas } \\
\text { alternativas de cultivo. }\end{array}$ \\
\hline
\end{tabular}

Continua... 


\begin{tabular}{|c|c|c|c|c|}
\hline $\begin{array}{l}\text { Título/ Referência } \\
\qquad(*)\end{array}$ & Ano/ País & $\begin{array}{l}\text { Delineamento/ } \\
\text { Número de } \\
\text { Participante }\end{array}$ & Intervenções & Considerações do estudo \\
\hline $\begin{array}{l}\text { Percepção de risco: } \\
\text { maneiras de pensar } \\
\text { e agir no manejo de } \\
\text { agrotóxicos }\end{array}$ & 2007/Brasil & $\begin{array}{c}\text { Abordagem } \\
\text { antropológica } \\
\text { inspirada no modelo } \\
\text { de Signos com vinte } \\
\text { trabalhadores }\end{array}$ & $\begin{array}{l}\text { Identificação dos } \\
\text { elementos que } \\
\text { influenciam as } \\
\text { percepções e } \\
\text { ações relacionadas } \\
\text { ao uso de } \\
\text { agrotóxicos na } \\
\text { produção de flores } \\
\text { ornamentais }\end{array}$ & $\begin{array}{c}\text { Os trabalhadores enfrentam } \\
\text { duas realidades paradoxais: a } \\
\text { necessidade do agrotóxico e } \\
\text { o sofrimento gerado pelo seu } \\
\text { manejo }\end{array}$ \\
\hline $\begin{array}{l}\text { Nível de entendimento } \\
\text { das informações de } \\
\text { primeiros socorros } \\
\text { de bula e rótulo de } \\
\text { agrotóxico por meeiros } \\
\text { de plantações de } \\
\text { tomate de Sumaré, SP }\end{array}$ & 2008/Brasil & $\begin{array}{c}\text { Pesquisa aplicada e } \\
\text { quantitativa, do tipo } \\
\text { transversal, com } 80 \\
\text { meeiros }\end{array}$ & $\begin{array}{l}\text { Avaliação do nível } \\
\text { de entendimento } \\
\text { de meeiros de } \\
\text { plantações de } \\
\text { tomate acerca das } \\
\text { informações de } \\
\text { Primeiros Socorros } \\
\text { que constam em } \\
\text { bula/rótulo de } \\
\text { agrotóxicos }\end{array}$ & $\begin{array}{l}\text { Existe uma dificuldade na } \\
\text { compreensão dos dados } \\
\text { contidos nas bulas. } \\
\text { Conclui-se que bulas e rótulos } \\
\text { de agrotóxicos devem ser } \\
\text { simplificados, com informações } \\
\text { dirigidas e adaptadas ao público } \\
\text { alvo para educar e orientar os } \\
\text { trabalhadores rurais }\end{array}$ \\
\hline $\begin{array}{l}\text { Knowledge, Attitudes, } \\
\text { Practices and } \\
\text { Biomonitoring of } \\
\text { Farmers and Residents } \\
\text { Exposed to Pesticides } \\
\text { in Brazil }\end{array}$ & 2012/Brasil & $\begin{array}{c}\text { Pesquisa aplicada } \\
\text { com } 112 \text { trabalhadores } \\
\text { rurais }\end{array}$ & $\begin{array}{l}\text { Avaliação dos } \\
\text { conhecimentos, } \\
\text { atitudes e práticas } \\
\text { em matéria } \\
\text { de utilização } \\
\text { de pesticidas } \\
\text { e os níveis de } \\
\text { exposição dos } \\
\text { agricultores e } \\
\text { moradores para } \\
\text { organofosforados } \\
\text { e/ ou carbamatos }\end{array}$ & $\begin{array}{l}\text { Programas de educação especial } \\
\text { são necessários nessas regiões } \\
\text { para promover o uso seguro } \\
\text { de pesticidas no campo para } \\
\text { diminuir os riscos da exposição } \\
\text { a pesticidas aos agricultores, e } \\
\text { da exposição secundária a estes } \\
\text { compostos para suas famílias }\end{array}$ \\
\hline $\begin{array}{l}\text { Utilização do modelo } \\
\text { FPEEEA (OMS) para } \\
\text { a análise dos riscos } \\
\text { relacionados ao uso } \\
\text { de agrotóxicos em } \\
\text { atividades agrícolas } \\
\text { do estado do Rio de } \\
\text { Janeiro }\end{array}$ & 2012/Brasil & $\begin{array}{l}\text { Estudo descritivo- } \\
\text { exploratório, de base } \\
\text { qualitativa partir do } \\
\text { levantamento de } \\
\text { documentos oficiais } \\
\text { públicos e de revisão } \\
\text { de literatura (nacional } \\
\text { e internacional) }\end{array}$ & $\begin{array}{l}\text { Caracterização dos } \\
\text { riscos à saúde do } \\
\text { trabalhador rural } \\
\text { e ao ambiente } \\
\text { decorrentes do } \\
\text { uso intensivo de } \\
\text { agrotóxicos por } \\
\text { meio do Modelo } \\
\text { de FPEEEA (OMS) }\end{array}$ & $\begin{array}{c}\text { Grande parte dos determinantes } \\
\text { identificados na Matriz FPEEEA } \\
\text { encontra-se relacionada às } \\
\text { deficiências nas ações de } \\
\text { fiscalização e vigilância do uso } \\
\text { de agrotóxicos e de assistência } \\
\text { técnica por parte do Poder } \\
\text { Público }\end{array}$ \\
\hline $\begin{array}{l}\text { Uso de agrotóxicos e } \\
\text { impactos econômicos } \\
\text { sobre a saúde. Rev. } \\
\text { saúde pública }\end{array}$ & 2012/Brasil & $\begin{array}{c}\text { Pesquisa com } \\
\text { microdados da } \\
\text { Pesquisa de Previsão } \\
\text { de Safras (PREVS) do } \\
\text { IBGE }\end{array}$ & $\begin{array}{l}\text { Estimativa das } \\
\text { externalidades } \\
\text { associadas às } \\
\text { intoxicações } \\
\text { agudas por } \\
\text { agrotóxicos }\end{array}$ & $\begin{array}{l}\text { A sociedade, em especial as } \\
\text { populações mais atingidas pelos } \\
\text { agrotóxicos, seriam beneficiadas } \\
\text { se riscos de intoxicação aguda } \\
\text { associados ao atual modelo } \\
\text { de produção agrícola fossem } \\
\text { reconhecidos e eliminados }\end{array}$ \\
\hline $\begin{array}{l}\text { Percepção de risco, } \\
\text { atitudes e práticas no } \\
\text { uso de agrotóxicos } \\
\text { entre agricultores de } \\
\text { Culturama, MS }\end{array}$ & 2008/Brasil & $\begin{array}{l}\text { Estudo qualitativo } \\
\text { com sete grupos } \\
\text { focais, totalizando } 40 \\
\text { participantes }\end{array}$ & $\begin{array}{l}\text { Avaliação da } \\
\text { percepção de } \\
\text { risco, das práticas } \\
\text { e atitudes no uso } \\
\text { de agrotóxicos por } \\
\text { agricultores }\end{array}$ & $\begin{array}{c}\text { Os agricultores nem sempre } \\
\text { transformam sua percepção de } \\
\text { risco e suas experiências pessoais } \\
\text { em atitudes e práticas mais } \\
\text { seguras no uso de agrotóxicos, } \\
\text { como o uso adequado de } \\
\text { equipamentos de proteção } \\
\text { individual }\end{array}$ \\
\hline
\end{tabular}

Continua... 


\begin{tabular}{|c|c|c|c|c|}
\hline $\begin{array}{c}\text { Título/ Referência } \\
\left({ }^{*}\right)\end{array}$ & Ano/ País & $\begin{array}{l}\text { Delineamento/ } \\
\text { Número de } \\
\text { Participante }\end{array}$ & Intervenções & Considerações do estudo \\
\hline $\begin{array}{c}\text { Percepção das } \\
\text { condições de trabalho } \\
\text { em uma tradicional } \\
\text { comunidade agrícola } \\
\text { em Boa Esperança, } \\
\text { Nova Friburgo, Rio de } \\
\text { Janeiro, Brasil }\end{array}$ & 2004/Brasil & Estudo qualitativo & $\begin{array}{l}\text { Aplicação de uma } \\
\text { metodologia de } \\
\text { diagnóstico rápido } \\
\text { para a avaliação } \\
\text { da percepção } \\
\text { de riscos no } \\
\text { trabalho rural } \\
\text {-relacionada ao } \\
\text { uso de produtos } \\
\text { agrotóxicos }\end{array}$ & $\begin{array}{c}\text { Os estudo evidenciou o } \\
\text { desenvolvimento de estratégias } \\
\text { de defesa frente aos perigos } \\
\text { vivenciados no trabalho, as } \\
\text { respostas subjetivas frente a } \\
\text { situações de potencial dano à } \\
\text { saúde e o papel da percepção } \\
\text { individual e coletiva dos riscos na } \\
\text { determinação da exposição aos } \\
\text { agrotóxicos }\end{array}$ \\
\hline $\begin{array}{l}\text { Trabalho rural e fatores } \\
\text { de risco associados } \\
\text { ao regime de uso de } \\
\text { agrotóxicos em Minas } \\
\text { Gerais, Brasil }\end{array}$ & 2003/Brasil & $\begin{array}{c}\text { Pesquisa quantitativa- } \\
\text { Regressão } \\
\text { logística com } 1.064 \\
\text { trabalhadores rurais, } \\
\text { entre os anos de } 1991 \\
\text { a } 2000\end{array}$ & $\begin{array}{l}\text { Caracterização } \\
\text { do processo do } \\
\text { trabalho rural em } \\
\text { nove municípios } \\
\text { de Minas Gerais, } \\
\text { relacionado ao } \\
\text { uso de agrotóxicos } \\
\text { e a intoxicação } \\
\text { associada a seu } \\
\text { uso }\end{array}$ & $\begin{array}{c}\text { Alto grau de risco de agravos } \\
\text { à saúde a que estão sujeitos } \\
\text { trabalhadores rurais em contato } \\
\text { com agrotóxicos }\end{array}$ \\
\hline $\begin{array}{c}\text { Saúde e ambiente } \\
\text { em sua relação com o } \\
\text { consumo de agrotóxicos } \\
\text { em um polo agrícola } \\
\text { do Estado do Rio de } \\
\text { Janeiro, Brasil }\end{array}$ & 2007/Brasil & $\begin{array}{c}\text { Utilização de } \\
\text { resultados de estudos } \\
\text { desenvolvidos por } \\
\text { grupo de pesquisa } \\
\text { durante nove anos na } \\
\text { região }\end{array}$ & $\begin{array}{c}\text { Discussão } \\
\text { sobre algumas } \\
\text { implicações do } \\
\text { uso de agrotóxicos } \\
\text { para a saúde } \\
\text { humana e o } \\
\text { ambiente da } \\
\text { região serrana do } \\
\text { Estado do Rio de } \\
\text { Janeiro }\end{array}$ & $\begin{array}{l}\text { Necessidade de se integrar os } \\
\text { setores saúde e ambiente em } \\
\text { torno da garantia da qualidade } \\
\text { de vida das populações do } \\
\text { campo e da cidade, tendo } \\
\text { como conceito norteador a } \\
\text { sustentabilidade ambiental }\end{array}$ \\
\hline $\begin{array}{c}\text { Impacto dos } \\
\text { praguicidas na saúde: } \\
\text { estudo da cultura de } \\
\text { tomate }\end{array}$ & 2000/Brasil & $\begin{array}{l}\text { Pesquisa quantitativa } \\
\text { com um total de } 186 \\
\text { entrevistados }\end{array}$ & $\begin{array}{l}\text { Obtenção do } \\
\text { conhecimento } \\
\text { sobre o risco para } \\
\text { a população, } \\
\text { foi estudada a } \\
\text { utilização de } \\
\text { praguicidas } \\
\text { em tomates } \\
\text { produzidos em } \\
\text { Pernambuco }\end{array}$ & $\begin{array}{l}\text { As duas regiões estudadas } \\
\text { carecem, indiscriminadamente, } \\
\text { de ações que visem à proteção } \\
\text { da saúde dos trabalhadores } \\
\text { rurais, que lidam com os } \\
\text { praguicidas, e de medidas contra } \\
\text { os danos para o meio ambiente, } \\
\text { que se encontra gravemente } \\
\text { comprometido }\end{array}$ \\
\hline $\begin{array}{l}\text { Farmworker reports of } \\
\text { pesticide safety and } \\
\text { sanitation in the work } \\
\text { environment }\end{array}$ & $\begin{array}{l}\text { 2001/ } \\
\text { Estados } \\
\text { Unidos da } \\
\text { América }\end{array}$ & $\begin{array}{c}\text { Pesquisa } \\
\text { formativa com } 270 \\
\text { trabalhadores rurais } \\
\text { em 1998, e } 293 \\
\text { durante } 1999 .\end{array}$ & $\begin{array}{l}\text { Desenvolver } \\
\text { medidas eficazes } \\
\text { para melhorar } \\
\text { a segurança no } \\
\text { trabalho agrícola }\end{array}$ & $\begin{array}{c}\text { A ênfase na intervenção } \\
\text { deve incluir a educação dos } \\
\text { agricultores }\end{array}$ \\
\hline
\end{tabular}

A maior parte dos estudos foi publicada em 2012 (21,4\%), seguida dos anos 2009, 2008, 2007 e 2004 (aproximadamente 14\% cada) e dos anos 2003, 2001 e 2000 (7,2 \% cada). O Brasil concentra a maior parte das publicações (92,8\%), seguido dos Estados Unidos da América (aproximadamente 7,2\%). Referente ao delineamento dos estudos, quatorze eram descritivos (100\%) e conforme a classificação dos níveis de evidências ${ }^{10}$ foi constatado a totalidade dos estudos com nível de evidência ${ }^{6}$.

As produções apontam os principais fatores que influenciam na prevenção de agravos frente ao uso de agrotóxicos na atividade rural. Emergiram dados relacionados ao não uso de Equipamentos de Proteção Individual (EPI's), desconhecimento dos riscos no uso desses produtos e carência de políticas governamentais relativas ao tema. 
Diante dos artigos analisados, identificou-se que o não uso de EPI's, desconhecimento dos riscos no uso desses produtos e carência de políticas governamentais relativas ao tema são fatores que influenciam na prevenção de agravos frente ao uso de agrotóxicos de forma negativa, o que culmina em efeitos danosos à saúde do trabalhador rural.

Diante disso, a utilização dos praguicidas, no Brasil, tem trazido sérias consequências, tanto para o meio ambiente como para a saúde da população, especialmente do trabalhador rural. Isso porque, na maioria das vezes, o contexto da agricultura está condicionado ao modo de produção químico-dependente, pela toxicidade dos produtos utilizados, como agrotóxicos, pela precariedade dos mecanismos de vigilância da saúde, pelo uso inadequado ou falta de EPI's ${ }^{11}$.

As doenças ocupacionais e intoxicações acidentais são frequentes, devido à dificuldade na utilização de equipamentos de segurança ${ }^{1,12,13,14}$. Também há o problema da maioria dos trabalhadores rurais não compreenderem as instruções quanto ao uso seguro dos agrotóxicos, principalmente devido à baixa escolaridade ${ }^{1,12,15}$.

Em relação aos EPl's, existe a necessidade do uso desses equipamentos conforme determina a lei. Por outro lado, quando são utilizados, não está evidenciado que esses equipamentos são adequados para a atividade fim e as condições climáticas que variam de região para região. Conforme revelam alguns agricultores, eles não são usados por serem desconfortáveis, dificultarem a locomoção e provocarem calor excessivo ${ }^{16}$.

É fato que os EPI's protegem o trabalhador contra os riscos ocupacionais, contudo, muitas vezes são usados parcialmente ou negligenciados pelos trabalhadores e/ou empregadores, configurando a presença de risco ao adoecimento. Técnicos agrícolas e leigos têm concepções e saberes diferentes acerca do risco de adoecimento, o que suscita a necessidade de atenção para que não se restrinja à análise técnica dos riscos ocupacionais, sem considerar outras dimensões envolvidas. Fato que dificulta a apreensão do processo de trabalho e de informações que podem ser úteis na construção de políticas e estratégias de gestão do risco ${ }^{17}$.

A carência educacional e de formação dos agricultores contribui para a dificuldade na interpretação de informações sobre saúde e segurança no manuseio de agentes químicos perigosos, como os agrotóxicos ${ }^{6}$. Tais aspectos também se associam ao desconhecimento por parte dos produtores e aplicadores de praguicidas no que se refere aos efeitos tóxicos para a saúde e o meio ambiente, associados ao uso indevido de praguicidas ${ }^{18}$.

Nesse sentido, as bulas e os rótulos dessas substâncias devem ser simplificados, conter informações dirigidas e adaptadas ao público-alvo para educar e orientar os trabalhadores rurais ${ }^{15}$, pois há relatos de queixas relacionadas ao tamanho das letras e da linguagem técnica do rótulo e da bula ${ }^{19}$. Isso se confirma no perfil socioeconômico que mostra percentuais expressivos de analfabetismo e baixa renda ${ }^{20}$.

O nível de escolaridade foi outro fator determinante na ocorrência das intoxicações. Pois o expressivo número de produtores rurais com baixa escolaridade dificulta o entendimento das instruções contidas na bula do produto, não só quanto à sua forma de aplicação, mas também em relação à periculosidade. Com isso, deve ser recomendada a elaboração de rótulos que facilitem o processo informativo e comunicativo para o agricultor ${ }^{16}$. A ação educativa pode, assim, ser concretizada quando esses não forem considerados meros espectadores num processo de diagnóstico, mas participarem da avaliação de seu sistema produtivo, percebendo problemas e discutindo, em roda, possibilidades de intervenções corretivas para a produção agrícola ${ }^{21}$.

O uso de agrotóxicos é uma rotina para os trabalhadores rurais e apesar de existir uma naturalização do uso, os agricultores acreditam que os agrotóxicos podem afetar sua saúde ${ }^{20,13}$, apresentam preocupação com o consumidor e gostariam de conhecer formas alternativas de cultivo ${ }^{20}$. Esses dados despontam para a possibilidade de mudança nas práticas. A alternativa de uma agricultura sem agrotóxicos é a de base ecológica, que vem a ser um sistema agrícola, com vistas a promover e a saúde humana e ambiental, preservar a biodiversidade, os ciclos e as atividades biológicas do solo ${ }^{22}$.

Outro fator importante para um futuro menos agressivo é o incentivo à produção mais limpa, como a produção orgânica e a utilização de agentes de controle biológico para a redução de danos no campo. Com a sensibilização do produtor rural, mostrando a gravidade da utilização sem controle de agrotóxicos, a existência de outras formas de controle mais limpas e eficientes, bem como diferentes formas de agregar valor ao seu produto, pode-se pensar em uma agricultura mais sustentável, que mantenha os níveis de produtividade, garantindo alimentação para a população, sem elevar os níveis de contaminação ambiental e nem prejudicar a saúde humana ${ }^{23}$.

Não se trata de repasse de conhecimento, pois este tipo de informação, de alguma forma, eles já possuem. Tratase de desenvolver estratégias objetivando a minimização dos riscos ou mesmo o desuso de agrotóxicos na lavoura ${ }^{20}$, com vistas a sensibilizar os agricultores ${ }^{24,25}$. Esse é um grande desafio proposto aos profissionais de saúde. 
Nesse sentido, a educação ambiental desempenha importante papel na agregação de elementos, como a participação dos trabalhadores rurais em todas as etapas do processo; o desenvolvimento de uma percepção acerca da situação socioambiental e o estímulo à capacidade de reflexão de cada indivíduo e do grupo, analisando seu espaço de vivência/produção, suas atividades diárias, suas relações sociais e políticas, dentre outros ${ }^{21}$.

Assim, profissionais de saúde, biólogos, ambientalistas, agrônomos são alguns dos profissionais que podem contribuir para a prevenção de agravos decorrentes do trabalho no ambiente rural, buscando mudanças no atual modelo químico-dependente. Por isso, conhecer o ambiente rural e as condições de vida desses trabalhadores, é fundamental para tecer reflexões acerca da saúde individual, coletiva e ambiental, constituindo-se em um fator preditivo da criação de ambientes sustentáveis e saudáveis ${ }^{17}$.

Os dados indicam ${ }^{26}$ que esses trabalhadores rurais encontram-se em situações paradoxais: a necessidade do agrotóxico e o dano gerado pelo seu manejo. Somado a isso, as deficiências nas ações de fiscalização e vigilância do uso de agrotóxicos e de assistência técnica por parte do Poder Público ${ }^{27,28}$ (A7, A8). Por falta de estrutura e de pessoal, os órgãos que fazem a fiscalização no campo até hoje não conseguiram cumprir amplamente seu papel de monitorização adequada das normas quanto à comercialização e utilização dos pesticidas, como o número de aplicações, dosagens, períodos de carência e uso de produtos ilegais ${ }^{29}$.

Essa lacuna relacionada às políticas governamentais voltadas ao acompanhamento e fiscalização das atividades do homem do campo afastam, ainda mais, esses indivíduos dos saberes disponíveis sobre as práticas de proteção de lavouras e combate às pragas ${ }^{6}(\mathrm{~A} 12)$. A fiscalização de todo o ciclo de vida destes produtos, desde as matérias-primas até 0 descarte, poderiam reduzir os impactos ambientais e, se conduzidas de forma segura, também os problemas relacionados à contaminação humana (trabalhadores da produção, trabalhadores rurais e consumidores) ${ }^{23}$.

Exemplos de medidas que podem minimizar os riscos do uso dos agrotóxicos são multas pelo não cumprimento da legislação específica, uso de EPI, fiscalização, posto ou central de recebimento de embalagens, respeito ao período de carência, uso do receituário agronômico, programas de educação ambiental, vigilância da saúde dos trabalhadores e impactos ambientais, monitoramento da água e do solo, monitoramento do limite de tolerância dos alimentos consumidos e incentivo à agroecologia ${ }^{30}$. A participação ativa e organizada de sujeitos coletivos na elaboração e implementação de políticas públicas intersetoriais podem promover melhoria das condições de trabalho e vida ${ }^{31}$. Assim, são essenciais programas governamentais de extensão agrícola, que enfatizem técnicas alternativas de manejo de pragas e práticas seguras de uso de agrotóxicos, direcionados a essa população ${ }^{19}$.

Nesse ínterim, visto que os agricultores nem sempre transformam sua percepção de risco e suas experiências pessoais em atitudes e práticas mais seguras no uso de agrotóxicos, é imperativo que os profissionais de enfermagem conheçam os riscos a que trabalhadores estão expostos e os fatores que influenciam na prevenção de agravos, de forma a incorporar em sua prática medidas que visem a proteção e recuperação da saúde, numa abordagem ecossistêmica, respeitando as especificidades dessa clientela.

\section{Considerações Finais}

As evidências dos estudos selecionados revelam que o não uso de EPl's, o desconhecimento dos riscos do uso desses produtos e a carência de políticas governamentais relacionadas ao tema são fatores que influenciam negativamente na prática de prevenção de agravos frente ao risco do uso dos agrotóxicos. Desse modo, revela-se necessário que os profissionais de enfermagem compreendam esses fatores com o intuito de prestar um cuidado de excelência aos trabalhadores rurais, que leve em consideração as especificidades dessa clientela. Isso exige da enfermagem uma postura ativa diante da problemática, com vistas à minimização desses riscos.

Portanto, os profissionais de enfermagem e as indústrias/laboratórios devem investir em atividades educativas que ratifiquem a importância do uso dos EPI's, além de prestar esclarecimentos sobre os riscos do uso dos agrotóxicos para a saúde e para o meio ambiente, como as intoxicações agudas e crônicas e a poluição ambiental, para que juntos possam fortalecer suas ações em prol do bem-estar dos trabalhadores rurais. Ainda, a criação de políticas e programas que contemplem a promoção de saúde e prevenção de agravos advindos da utilização de agrotóxicos pelas instâncias governamentais é uma sugestão para proteger a saúde desses trabalhadores. 


\section{Referências}

1. Jacobson LSV Hacon SS, Alvarenga L, Goldstein RA, Gums C, Buss DF, Leda LR. Comunidade pomerana e uso de agrotóxicos: uma realidade pouco conhecida. Ciênc. saúde coletiva. 2009; 14(6):2239-49.

2. Carneiro FF, Pignati W, Rigotto RM, Augusto LGS, Rizollo A, Muller NM et al. Dossiê ABRASCO -Um alerta sobre os impactos dos agrotóxicos na saúde. 1. Parte. ABRASCO, Rio de Janeiro; 2012.

3. Ministério da Saúde (Brasil), Secretaria de Vigilância em Saúde. Dados e Indicadores Selecionados: II Informe Unificado das Informações sobre Agrotóxicos Existentes no SUS. Edição Especial. Brasília; 2008.

4. Ministério da Saúde (Brasil). Plano integrado de vigilância em saúde de populações expostas a agrotóxicos. Brasília; 2009.

5. Siqueira SL, Kruse MHL. Agrotóxicos e Saúde Humana: contribuição dos profissionais do campo da saúde. Rev. Esc. Enferm. USP. 2008; 42(3):584-90.

6. Peres F, Moreira JC. Saúde e ambiente em sua relação com o consumo de agrotóxicos em um pólo agrícola do Estado do Rio de Janeiro, Brasil. Cad. saúde pública. 2007; 23(4):612-21.

7. Araújo AJ, Lima JS, Moreira JC, Jacob SC, Soares MO, Monteiro MCM et al. Exposição múltipla a agrotóxicos e efeitos à saúde: estudo transversal em amostra de 102 trabalhadores rurais, Nova Friburgo, RJ. Ciênc. saúde coletiva. 2007; 12(1):115-130.

8. Pompeu DA, Rossi LA, Galvão CM. Revisão integrativa: etapa inicial do processo de validação de diagnóstico de enfermagem. Acta paul. enferm. 2009; 22(4):434-8.

9. Mendes KDS, Silveira RCCP, Galvão CM. Revisão integrativa: método de pesquisa para a incorporação de evidências na saúde e na enfermagem. Texto \& contexto enferm. 2008; 17(4):758-64.

10. Melnyk BM, Fineout-Overholt E. Making the case for evidence-based practice. In: Melnyk BM, Fineout- Overholt E, editors. Evidence-based practice in nursing and healthcare: a guide to best practice. 1st ed. Philadelphia: Lippincott Williams and Wilkins; 2005. p. 3-24.

11. Augusto LGS, Carneiro FF, Pignati W, Rigotto RM, Friedrich K, Faria, NM et al. Associação Brasileira de Saúde Coletiva Dossiê ABRASCO - Um alerta sobre os impactos dos agrotóxicos na saúde. Parte 2 - Agrotóxicos, Saúde, Ambiente e Sustentabilidade. ABRASCO, Rio de Janeiro; 2012.

12. Domingues MR, Bernardi, MR, Ono EYS, Ono MA. Agrotóxicos: Risco à Saúde do Trabalhador Rural. Semina cienc. biol. saúde. 2004 jan-dez; 25(1):45-54.

13. Pasiani JO, Torres P, Silva JR, Diniz BZ, Caldas ED. Knowledge, Attitudes, Practices and Biomonitoring of Farmers and Residents Exposed to Pesticides in Brazil. Int. J. Environ. Res. Public Health. 2012; 9(9):3051-68.

14. Soares W, Almeida RMVR, Moro S. Trabalho rural e fatores de risco associados ao regime de uso de agrotóxicos em Minas Gerais, Brasil. Cad. saúde pública. 2003 jul-ago; 19(4):1117-27.

15. Tomazin CC, Zambrone FAD. Nível de entendimento das informações de primeiros socorros de bula e rótulo de agrotóxico por meeiros de plantações de tomate de Sumaré, SP. Rev. bras. toxicol. 2008; 21(1): 20-4.

16. Soares WL, Freitas EAV, Coutinho JAG. Trabalho rural e saúde: intoxicações por agrotóxicos no município de Teresópolis - RJ. Rev. Econ. Sociol. Rural. 2005; 43(4): 685-701.

17. Menegat RP, Fontana RT. Condições de trabalho do trabalhador rural e sua interface com o risco de adoecimento. Ciênc. cuid. saúde. 2010; 9(1):52-59.

18. Araújo ACP, Nogueira DP, Augusto LGS. Impacto dos praguicidas na saúde: estudo da cultura de tomate. Rev. saúde pública. 2000; 34(3):309-13.

19. Recena MCP, Caldas ED. Percepção de risco, atitudes e práticas no uso de agrotóxicos entre agricultores de Culturama, MS. Rev. saúde pública. 2008; 42(2):294-301.

20. Brito PF, Gomide M, Câmara VM. Agrotóxicos e saúde: realidade e desafios para mudança de práticas na agricultura. Physis (Rio J.). 2009; 19(1):207-25.

21. Lima EACF, Araujo CAM, Sant'Ana AL, Carvalho SL. Educação ambiental em uma comunidade de agricultores familiares: resgate histórico e reflexões sobre as intervenções educativas realizadas. Rev. eletrônica Mestr. Educ. Ambient. 2011; 26(1):76-86.

22. Porto MF, Soares WL. Modelo de desenvolvimento, agrotóxicos e saúde: um panorama da realidade agrícola brasileira e propostas para uma agenda de pesquisa inovadora. Rev. bras. saúde ocup. 2012; 37(125):17-50.

23. Ribas PP, Matsumura ATS. A química dos agrotóxicos: impacto sobre a saúde e ensino. Rev. Liberato. 2009; 10(14):149-58. 
24. Arcury TA, Quandt SA, Cravey AJ, Elmore RC, Russell GB. Farmworker reports of pesticide safety and sanitation in the work environment. Am J Ind Med. 2001 May; 39(5):487-98.

25. Peres F, Lucca SR, Ponte LMD, Rodrigues KM, Rozemberg B. Percepção das condições de trabalho em uma tradicional comunidade agrícola em Boa Esperança, Nova Friburgo, Rio de Janeiro, Brasil. Cad. saúde pública. 2004 jul-ago; 20(4):1059-68. 26. Fonseca MGU, Peres F, Firmo JOA, Uchôa E. Percepção de risco: maneiras de pensar e agir no manejo de agrotóxicos. Ciênc. saúde coletiva. 2007; 12(1):39-50.

27. Araújo-Pinto M, Peres F, Moreira JC. Utilização do modelo FPEEEA (OMS) para a análise dos riscos relacionados ao uso de agrotóxicos em atividades agrícolas do estado do Rio de Janeiro. Ciênc. saúde coletiva. 2012; 17(6):1543-55. 28. Soares WL, Porto MFS. Uso de agrotóxicos e impactos econômicos sobre a saúde. Rev. saúde pública. 2012; 46(2):209-17. 29. Londres F. Agrotóxicos no Brasil: um guia para ação em defesa da vida. - Rio de Janeiro: AS-PTA - Assessoria e Serviços a Projetos em Agricultura Alternativa, 2011.

30. Soares WL, PORTO MFS. Atividade agrícola e externalidade ambiental: uma análise a partir do uso de agrotóxicos no cerrado brasileiro. Ciênc. saúde coletiva. 2007; 12(1):131-43.

31. Scopinho RA. Condições de vida e saúde do trabalhador em assentamento rural. Ciênc. saúde coletiva. 2010; 15(1):1575-84.

\section{Cibelle Mello Viero}

Endereço para correspondência - Rua: 24 de Maio, $n^{\circ} 285$,

Vila Oliveira, CEP: 97020710 , Santa Maria, RS, Brasil.

E-mail: cibellemelloviero@gmail.com

Lattes: http://lattes.cnpq.br/7140237160056448

Silviamar Camponogara - silviaufsm@yahoo.com.br

\section{Enviado em 03 de fevereiro de 2014. Aceito em 13 de agosto de 2015.}


